\title{
Insights into the pathogenesis of Mycoplasma pneumoniae (Review)
}

\author{
JUN HE ${ }^{1,2}$, MIHUA LIU ${ }^{1}$, ZHUFENG YE ${ }^{1}$, TIANPING TAN ${ }^{1}$, XINGHUI LIU ${ }^{1}$, \\ XIAOXING YOU ${ }^{2}$, YANHUA ZENG ${ }^{2}$ and YIMOU $\mathrm{WU}^{2}$ \\ ${ }^{1}$ Department of Clinical Laboratory, Nanhua Affiliated Hospital; ${ }^{2}$ Pathogenic Biology Institute, \\ University of South China, Hengyang, Hunan 421001, P.R. China
}

Received August 24, 2015; Accepted August 25, 2016

DOI: $10.3892 / \mathrm{mmr} .2016 .5765$

\begin{abstract}
Mycoplasma are the smallest prokaryotic microbes present in nature. These wall-less, malleable organisms can pass through cell filters, and grow and propagate under cell-free conditions in vitro. Of the pathogenic Mycoplasma Mycoplasma pneumoniae has been examined the most. In addition to primary atypical pneumonia and community-acquired pneumonia with predominantly respiratory symptoms, $M$. pneumoniae can also induce autoimmune hemolytic anemia and other diseases in the blood, cardiovascular system, gastrointestinal tract and skin, and can induce pericarditis, myocarditis, nephritis and meningitis. The pathogenesis of M. pneumoniae infection is complex and remains to be fully elucidated. The present review aimed to summarize several direct damage mechanisms, including adhesion damage, destruction of membrane fusion, nutrition depletion, invasive damage, toxic damage, inflammatory damage and immune damage. Further investigations are required for determining the detailed pathogenesis of M.pneumoniae.
\end{abstract}

\section{Contents}

1. Introduction

2. Direct damage mechanisms

3. Immune damage

4. Conclusion and perspective

\section{Introduction}

Mycoplasma are the smallest prokaryotic microbes present in nature. These wall-less, malleable organisms can pass through cell filters, and can grow and propagate under cell-free conditions in vitro (1). Mycoplasma contain a 600-1,350 kbp

Correspondence to: Professor Yimou Wu, Pathogenic Biology Institute, University of South China, 28 Changshengxi Road, Hengyang, Hunan 421001, P.R. China

E-mail: yimouwu@sina.com

Key words: mycoplasma pneumoniae, pathogenesis, damage, immune, adhesion genome and $23-35 \%$ GC. They reproduce predominantly via typical binary fission and have a tendency to form 'fried egg' colonies in solid culture media. At present, seven species of Mycoplasma have been found to be pathogenic to humans, including $M$. pneumoniae, M. urealytium, M. genitalium, $M$. hominis, M. fermentation, $M$. penetrans and M. pirum (1). M. pneumoniae, which was initially separated, cultivated and named by Chanock and Hayflick in 1962, has been examined the most (2). In addition to primary atypical pneumonia and community-acquired pneumonia, which induce predominantly respiratory symptoms, $M$. pneumoniae can also induce autoimmune hemolytic anemia and other diseases in the blood, cardiovascular system, gastrointestinal tract, and skin, and can induce pericarditis, myocarditis, nephritis and meningitis (3-5).

M.pneumoniae infections are distributed globally with local prevalence. As reported, its infection rate is increasing annually, however, the specific pathogenic mechanism remains to be fully elucidated (2). The pathogenesis of M. pneumoniae infection is complex as it involves several mechanisms, including adhesion damage, membrane fusion damage, nutrition depletion, invasive damage, toxic damage, immune damage and inflammatory damage (Fig. 1). However, the specific mechanism underlying its effects remains to be elucidated.

\section{Direct damage mechanisms}

Adhesion damage. The adhesion of $M$. pneumoniae onto the respiratory epithelia is a precondition dictating the propagation and pathogenesis of $M$. pneumoniae (6). In addition to pseudo-stratified columnar ciliated epithelia, M. pneumoniae can also adhere to red blood cells, HeLa cells, fibroblasts, macrophages and tracheal organ cultures in vitro, and can adhere to the surfaces of glass or plastics (7). M. pneumoniae is asymmetric under electron microscopy (8). The cell membranes at one end can extend outside to form a proline-rich top structure, also termed the apical organ, and specifically adhere onto the neuraminic acid receptors on the membranes of target cells.

Adhesion is an intricate process, as the adhesion structure consists of an interactive adhesion network-like system and adhesion auxiliary proteins. Specifically, the $170 \mathrm{kDa}$ P1 protein functions as a key ligand during adhesion (9). Pulse-tracking tag experiments have shown that $1 \mathrm{~h}$ following contact of $M$. pneumoniae with the target cells, the P1 precursor proteins, which are scattered in the cell membranes, 


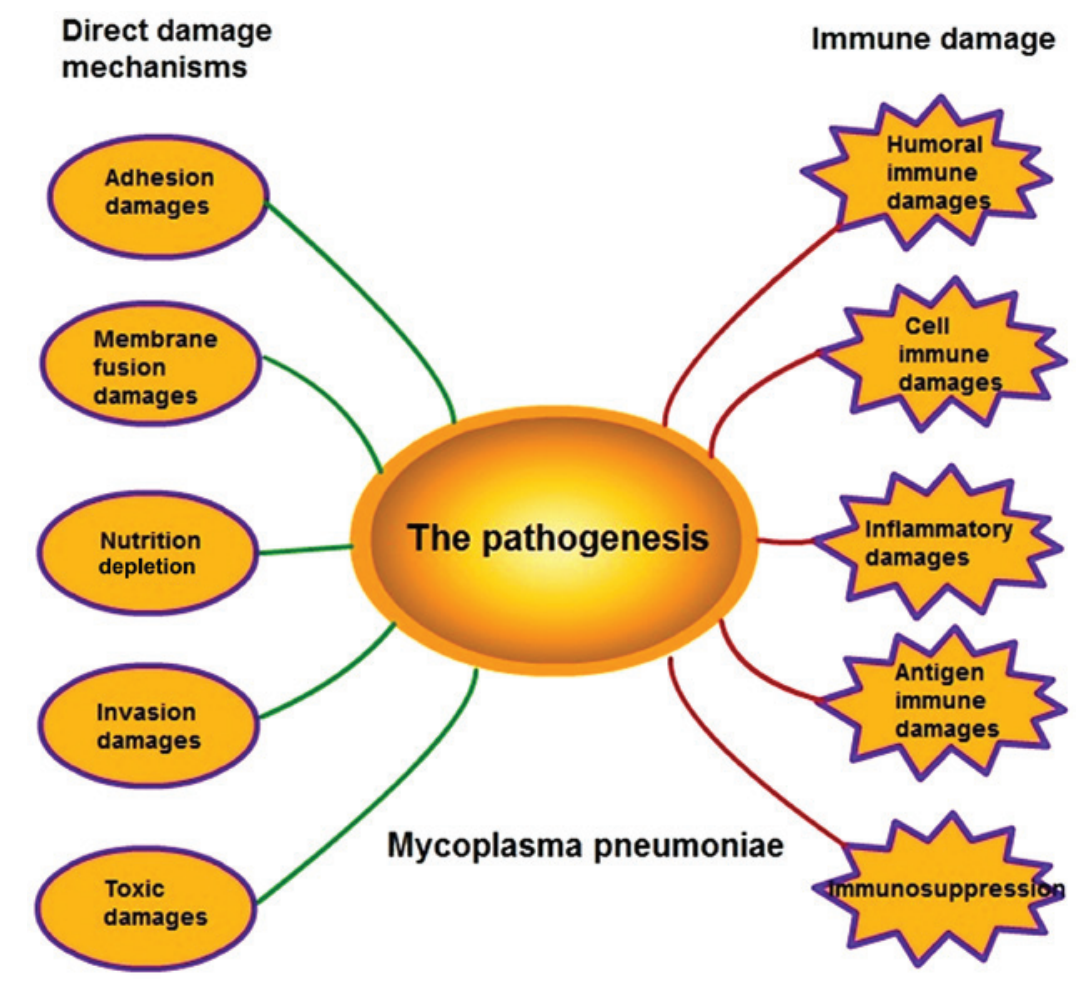

Figure 1. Pathogenesis of M. pneumoniae. The pathogenesis of M. pneumoniae comprises five direct damage mechanisms, including adhesion damage, membrane fusion damage, nutrition depletion, invasive damage, toxic damage, and five types of immune damage, including humoral immune damage, cell immune damage, inflammatory damage, antigen immune damage and immunosuppression.

rapidly shift to the apical organs, and the leading peptide on their amino terminal is hydrolyzed to mature P1 proteins (10). Due to its sole dependence on the key P1 protein, M. pneumoniae is unable to adhere to host cells, however, it can adhere with the assistance of several collaborative auxiliary proteins, including P30 adhesion factor-related protein A (72 KDa), $\mathrm{B}$ (85 KDa) and C (37 KDa), HMW 1-5 polypeptides, P40, P90 and $\mathrm{P} 65$; these components jointly constitute a characteristic high-electron-density 'adhesion protein complex' (Fig. 2) (11). This complex stabilizes the integrity of the M. pneumoniae apical structure by forming a cytoskeleton, anchoring the $\mathrm{P} 1$ protein into the cytoskeleton of the adhesive organs, and allowing the $\mathrm{P} 1$ proteins on the adhesion cell organs to adhere.

Marking experiments have shown that, in mutant strains with loss of adhesion auxiliary proteins, the $\mathrm{P} 1$ protein is chronically dispersed as a precursor in the cell membranes, however, it cannot aggregate to the apical organs or convert into mature P1 protein (9). Electron microscopy has demonstrated that the adhesion of a M. pneumoniae variant is concentrated in the adherend in the following order: HMW1, HMW3, Pl, P30, P90, P40 and P65, which indicates that these proteins have formed an interrelated adhesion network (12). Specifically, HMW1, HMW2 and HMW3 function as stable adherends and allow other adhesions to locate onto the adherend, and, they are involved in the adhesion onto the respiratory tract epithelia (13). As reported, the M. pneumoniae mutant strains, HMW1 and HMW2, can prevent the P1 protein from correctly locating onto the apical structure, which leads to irregular cell morphology, loss of toxicity and sliding ability, and loss of adhering function (14). P30 does not directly affect the positioning of the P1 protein onto the apical structure, however, it interferes with the binding between P1 and its receptor (15). The loss of P30 or enzymatic cleavage of the carboxyl terminal leads to the complete loss of adhesion function in M. pneumoniae, reduced sliding ability, and marked changes in morphology and structure (16). For example, a bifurcate structure appears in the apical tip, and numerous nucleoid-like substances appear in the cytoplasm. When transposon Tn4001 from the genes of an adhesion auxiliary protein C-mutant was used to transform M. pneumoniae, the mutant strain showed reduced cell adhesion ability. Following the loss of the P41 protein, the adherend in the sliding process of M. pneumoniae was separated from the cell (17). These adhesion auxiliary proteins and adhesion molecules jointly form adhesion protein complexes. The adsorption ability of host cells is decided by the positioning of adhesion proteins and the interaction between the components of the protein complexes.

M. pneumoniae can also utilize the MPN372 protein to combine with lung surfactant protein A (SP-A), pass through the host barrier and permanently adhere to target cells containing the SP-A receptor, including alveolar macrophages, alveolar epithelial type II cells, and other histiocytes inside and outside the lung (18). The pretreatment of M. pneumoniae with low-dose proenzyme reduces the binding between $M$. pneumoniae and SP-A by $80-90 \%$, however, pretreatment with mannose does not inhibit the binding between $M$. pneumoniae and SP-A, indicating that M. pneumoniae protein components are involved in this process (19).

Membrane fusion damage. The cell membranes of the Mycoplasma genus are more durable, compared with those of other prokaryotes, and the cytoskeletal protein network-like 


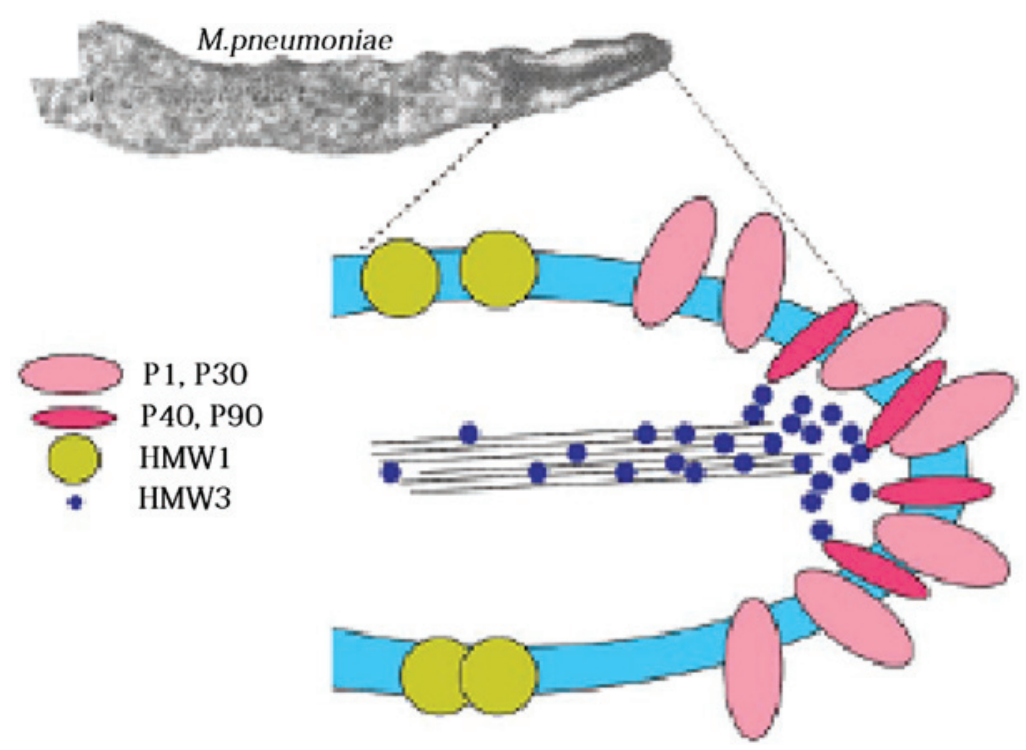

Figure 2. Structure of the Microplasma pneumoniae adhesion protein. The adhesion protein of M. pneumoniae includes key proteins P1 and P30, adhesion factor-associated proteins, P40, P90, HMW 1 and HMW 3. These components jointly constitute a characteristic high-electron-density 'adhesion protein complex'. This complex stabilizes the integrity of the M. pneumoniae apical organ structure by forming a cytoskeleton, anchoring the protein P1 to the cytoskeleton of the adhesive organs, and allowing the P1 proteins accumulating in the adhesion cell organs to adhere.

structure functions as a cell walls in terms of maintaining cell integrity. Following M. pneumoniae infection, the lipid bilayer of cell membranes is susceptible to biomembrane fusion, and its structure involves the transcription of specific genes, cytoskeletal changes and changes in the nucleolus (20). Membrane fusion can also cause changes in receptor-identifying sites in the cell membranes, affecting the signal delivery between cells and the production of cellular factors (21).

Nutrition depletion. The small-genome M. pneumoniae does not possess the ability to self-synthesize amino acids, fatty acids, cofactors or vitamins. Instead, following permanent adherence via the adherend to the respiratory tract epithelia, M.pneumoniae spreads microtubules and inserts them into host cells, enabling oxygen consumption, use of glucose, absorption of cholesterol, ingestion of amino acids and consumption of nutrients in host cells, causing injury to the host cells $(22,23)$.

Invasion damage. M. pneumoniae is usually regarded as an extracellular parasite, however, certain studies have shown it can also invade and damage cells. Studies have shown that M.pneumoniae can invade A549 lung cancer cells, evidenced by its detection in the cytoplasm and nucleus, and the invasive ability depends on the duration and temperature of infection (24). In cell culture in vitro, $M$. pneumoniae has been shown to invade non-phagocytes, survive for $>6$ months and synthesize DNA inside cells (7). When the clinically isolated RYC15989 strain was utilized to infect human Hep-G2 cells and rat N2A cells, intracellular Mycoplasma were observed under laser confocal microscopy, and the intracellular invasion damaging ability of M. pneumoniae was also confirmed (25). In addition, during invasion, certain enzymes inside $M$. pneumoniae, including hydrolase, nuclease and phosphoprotein phosphatase shift to the host cells. Nuclease degrades DNA in host cells, whereas phosphoprotein phosphatase interferes with the activity of serine/threonine and tyrosine protein kinase $(26,27)$.
Toxic damage. Adhesion provides conditions for $M$. pneumoniae to induce regional cytotoxic effects, and M.pneumoniae can directly induce damage via adhesion, auxiliary proteins, capsular and invasive enzymes. M. pneumoniae also exerts its toxin-like effects through its metabolites, exotoxin and exotoxin-like toxic substances, lipids, lipopolysaccharides and membrane lipoprotein (28). Following the adherence of $M$. pneumoniae onto the surface of bronchial cells, with the cytoskeleton rearrangement, $M$. pneumoniae penetrates through the bronchial mucous membranes and releases nuclease and $\mathrm{H}_{2} \mathrm{O}_{2}$, which result in swelling, necrosis and a binding of bronchial epithelial cells, slower microvilli movement, structural deformation, and the termination of swinging, thereby inducing the infiltration of lymphocytes, plasma cells and monocytes $(22,29)$. With the lack of superoxide dismutase and catalase in $M$. pneumoniae, the $\mathrm{H}_{2} \mathrm{O}_{2}$ and superoxide groups synthesized by $M$. pneumoniae, and the endogenous toxic oxygen molecules produced by the host cells, increase the intracellular oxygen pressure in the epithelium, which leads to oxidative stress and subsequent cell death (Fig. 3) (30). The major virulence factors affecting the pathogenesis of $M$. pneumoniae include the accumulation of $\mathrm{H}_{2} \mathrm{O}_{2}$ inside host cells and the effects of superoxides on the ultrastructure of host cells (31). The ions of M. pneumoniae-produced superoxides inhibit the activity and degradation of catalases in the host cells, so that the host cells become more sensitive to the toxic oxygen, resulting in mitochondrial swelling, vascular degeneration, cilia destruction and weakened cilia movement in the epithelium $(32,33)$. M. pneumoniae infection leads to the denaturation of red blood cell hemoglobin, loss of reduced glutathione and cytolysis $(34,35)$.

M. pneumoniae is considered to be incapable of secreting cytotoxin. The N-terminal of the $M$. pneumoniae-associated pathogenic factor, MPN372, contains ADP-ribose transferase activity and its structure is similar to the S1 subunit of pertussis toxin, which induces extensive vascular degeneration 


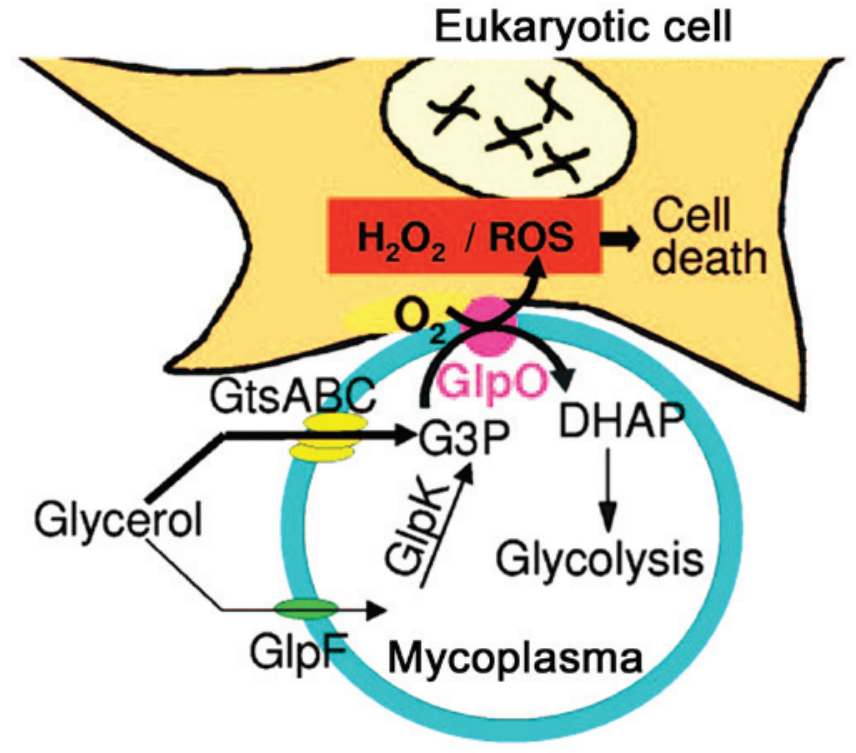

Figure 3. Toxic injury of Mycoplasma pneumoniae in glycerol. Following adherence of $M$. pneumoniae onto the surface of eukaryotic cells, cytoskeletal rearrangement occurs, and $\mathrm{H}_{2} \mathrm{O}_{2}$ and ROS are synthesized and released by $M$. pneumoniae in glycerol, which lead to oxidative stress and subsequent cell death. ROS, reactive oxygen species.

and can cause the death of mammalian cells, thereby inducing chincough-like clinical symptoms; these are termed community acquired respiratory distress syndrome (CARDS) toxin (36). M. pneumoniae CARDS toxin is internalized via clathrin-mediated endocytosis (37), and the CARDS toxin induces pulmonary eosinophilic and lymphocytic inflammation $(38,39)$. Cellular vacuoles induced by $M$. pneumoniae CARDS toxin originate from Rab9-associated compartments (40).

\section{Immune damage}

Clinical epidemiological findings show that the symptoms of M. pneumoniae infection are not observed at infancy, and that the pathogenic peak occurs in children $>10$ years old (41). In patients with reduced immune function, $M$. pneumoniae infection does not induce notable pathological changes in the lung. Experiments in thymus-excised animals have shown that $M$. pneumoniae infection does not readily induce pneumonia (42). Animal experiments have shown that the histopathologic response occurs 10-14 days following primary M. pneumoniae infection, but within 3 days following secondary infection, indicating that the body responds via immune cell accumulation following $M$. pneumoniae infection, but produces a more marked immune response to a second infection (43). These findings indicate that the host immune response is important during the onset of M. pneumoniae-induced pneumonia.

Humoral immune damage. The glycolipid antigen on the cell membranes of $M$. pneumoniae induces humoral immunity, and the antibody response is fundamental during the response against $M$. pneumoniae infection. At an early stage of M. pneumoniae infection, the body resists Mycoplasma settlement predominantly via a non-specific defense mechanism by secreting inhibitors, alexin and phagocytes (6). Animal experiments have shown that, following infection of the body with $M$. pneumoniae, the levels of complement components $\mathrm{C} 1, \mathrm{C} 2, \mathrm{C} 3$ and C4 in the bronchial secretions are significantly improved (44). After 2 weeks, the level of alexin begins to decline, whereas the antibody level increases, which indicates the non-specific protective effect of alexin at an early stage of M. pneumoniae infection (45). In children infected with M. pneumoniae, the contents of C1q, C3, C4 and B in the serum increase to varying degrees in the acute phase and recovery phase, indicating that the alexin classical and bypass activation pathways are involved during $M$. pneumoniae infection (46). With the lack of alexin, the surface of neutrophils have been shown to adhere with and engulf $M$. pneumoniae under electron microscopy, and the M. pneumoniae in their phagocytosis vesicles remains active (47). The specific sIgA produced during $M$. pneumoniae infection can protect against infection of respiratory mucous membranes, and its action is key in indigenous resistance (48). It was previously reported, that, 28 days following M. pneumoniae infection in pigs, the numbers of B cells in the alveolar lavage fluid and lung parenchyma increased 25-fold (49). In addition, in the acute phase and recovery phase of mycoplasma pneumonia, the contents of $\mathrm{IgG}, \operatorname{IgM}, \operatorname{IgA}$ and immune complex in the serum increase significantly, particularly in severely affected patients (50). Following M. pneumoniae infection, the $\operatorname{IgM}$ level has been shown to markedly increase in normal children, which usually occurred 7-14 days following infection, peaked in weeks 3-4 and persisted for months (51). M. pneumoniae infection can cause an increase in the level of total $\operatorname{IgE}$ in the serum, whereas delayed-type and anaphylactic-type allergic reactions induce asthma as an immediate reaction and delayed-phase reaction or a dual-phase reaction, which induce the IgE-mediated airway inflammation and airway hyper-reactivity (52). However, there is no direct evidence that M. pneumoniae is the direct cause of asthma. These previous studies indicate that various specific and nonspecific immunoglobulins and complement components are involved during $M$. pneumoniae infection, which assist with the recovery and immunity.

Cell immune damage. Cellular immunity is required by the protein antigens on the cell membranes of M. pneumoniae. Following inoculation with $M$. pneumoniae antibody in patients infected with $M$. pneumoniae, a tuberculin-like, delayed-type allergic reaction occurs to differing degrees; the reaction is more severe in severely-affected patients, however, this reaction can be inhibited by anti-thymocyte serum (53). Tuberculin tests in patients infected with M. pneumoniae show that the reaction intensity directly affects the degree of lung damage, indicating that cellular immunity is vital during the pathogenesis of $M$. pneumoniae (32). In patients with $M$. pneumoniae, the $\mathrm{CD}^{4+} \mathrm{T}$ cell count is decreased, the $\mathrm{CD}^{8+} \mathrm{T}$ cell count is markedly increased and the ratio of $\mathrm{CD}^{4+} \mathrm{T} / \mathrm{CD}^{8+}$ is reduced, and these changes are more marked in severely affected patients (53). In adults with M. pneumoniae infection, the peripheral blood $\mathrm{CD}^{4+} \mathrm{T}$ count is decreased, however, the ratio of T-lymphocytes to $\mathrm{CD}^{4+} / \mathrm{CD}^{8+}$ cells in the bronchoalveolar lavage fluid increases, possibly due to abundant $\mathrm{CD}^{4+} \mathrm{T}$ cells being involved in the inflammatory reaction (54). 
During M. pneumoniae infection, the Th1/Th2 ratio is unbalanced, although which type of cell is dominant remains controversial. It was previously reported that, following M. pneumoniae infection, Th1-dominated rats exhibit aggregation of peribronchial lymphocytes, whereas Th2-dominated rats exhibit hyperplasia of alveolus mesenchymal cells, which indicate that the imbalance in auxiliary T lymphocyte subgroups is associated with the type of lung damage (53). The mechanism underlying $M$. pneumoniae-induced asthma may be correlated with the enhanced secretion of Th2 cell factors (55).

Inflammatory damage. Inflammatory factors are important during the $M$. pneumoniae-induced inflammatory reaction. Polymerase chain reaction analysis has shown that, following primary M. pneumoniae infection in BALB/C rats, the mRNA expression levels of tumor necrosis factor- $\alpha$ (TNF- $\alpha)$, interleukin (IL)-1 $\beta$ and IL-6 in the lungs were markedly increased, whereas the mRNA expression levels of IL-2 and its receptor were not increased (56). Following the second infection, the mRNA expression levels of TNF- $\alpha$ and IL-6 increased 10-fold, whereas the mRNA expression of IL-2 decreased rapidly within $24 \mathrm{~h}$, and that of IL-10 increased markedly (56). It has been reported that $M$. pneumoniae can induce the production of IL-1 $\beta$, which is extensively involved in several types of damage, including tissue destruction and edema formation (57). Following M. pneumoniae infection, the serum level of IL-8 increases markedly, whereas white blood cells locate to the site of inflammation and infiltrate, accumulate and release active substances in the affected tissues, causing damage (58). The serum level of TNF- $\alpha$ following M.pneumoniae infection in the respiratory tract is significantly increased, and is positively correlated with the severity of illness (59). Serum levels of soluble IL-2 receptor (sIL-2R) can be an important indicator. In children with $M$. pneumoniae infection, the increase in the level of sIL-2R can reactivate the mononuclear cells in the circulation, and is involved in T lymphocyte dysfunction (60). In children with M. pneumoniae infection, the level of soluble intercellular adhesion molecule-1 is also markedly increased, which induces the increased bronchial reaction (61). M. pneumoniae antigens induce a potent immune reaction and enhance the Th17 cell response in vivo and in-vitro, with Treg and IL-10 being associated with the suppression of the production of IL-17A (62). The cytadherence of M. pneumoniae induces inflammatory responses through TLR4 and autophagy (6). $M$. pneumoniae infection has been shown to increase inflammatory factors in a rat model of atherosclerosis and aggravate the state of atherosclerosis (4).

\section{Antigen immune damage}

Antigenic variation. The M. pneumoniae membrane protein is associated with invasiveness, and its variation directly affects the toxicity of M. pneumoniae. The molecular weight of the $M$. pneumoniae membrane $\mathrm{V}-1$ antigen can change and is associated with virulence. No toxicity or pathogenesis occurs when its molecular weight is $100-200 \mathrm{kDa}$, however, toxicity and pathogenesis are observed when its molecular weight is $30 \mathrm{kDa}$. The gene mutation in V-1 antigen occurs at a 17-amino-acid repetitive sequence at the $\mathrm{C}$ terminal of the $94.2 \mathrm{kDa}$ antigen, whereas the $27.4 \mathrm{kDa}$ antigen contains two adjacent, but discontinuous, nine-amino-acid repetitive sequences, and variation is induced by site-specific DNA inversion (63). In addition, the adsorption of RBCs by $M$. pneumoniae can alter the antigenicity of RBC membranes and induce autoantibody against RBC membrane I antigen, namely the cold agglutinin of RBCs, which induces autoimmune hemolytic anemia (64).

Immune evasion. The Mycoplasma-induced viscous polysaccharide capsule, as with other bacteria, is readily formed inside the host, however, it disappears rapidly in vitro, indicating phagocytosis by the host cells. M. pneumoniae readily induces variation in surface membrane antigens, in order to evade attacks from the host immune system. M. pneumoniae may tightly adsorb onto the surface of the host cells, depending on the specific adhesion structure, to avoid phagocytosis prior to exact antibody adjustment (65). The polymorphism of $M$. pneumoniae adhesion antigens also weakens the effects of specific antibodies (66). The glycerophosphatide on $M$. pneumoniae cell membranes shares certain antigenic components with the host cells, and thus can also evade the host's immune surveillance. The invasion of intracellular parasitism assists in enabling $M$. pneumoniae to evade the host's immune clearance and drug effect. Therefore subjecting the patients to chronically infected persons or asymptomatic carriers. Thus, the various immune evasion mechanisms of M. pneumoniae constitute the predominant factor explaining why $M$. pneumoniae can survive chronically inside the host.

Cross-reacting antigen. The $M$.pneumoniae membrane antigen is in antigen mimic of the RBC-membrane I antigen, and shares certain antigenic components with Streptococcus pneumoniae 23 or 32 and M. genitalium (67). As with several plants and bacteria, the membrane glycolipids of $M$. pneumoniae share a common antigen in the brain and lung tissues, which induce cross reaction. The carboxyl end of the P1 and P30 proteins in the adhesive organs of M. pneumoniae show high levels of homology to the cytoskeletal proteins, fibrinogen, keratin and troponin in eukaryotes (68). Thus, during infection, autoantibodies in the brain, lung, RBC-membrane, lymphocytes and myocardial cells commonly occur, which form immune complexes and magnify the autoimmune response, leading to multisystem immune damage.

Superantigen. M. pneumoniae membranes are full of Mycoplasma lipid-associated membrane proteins. At least three types of functional protein have been identified, including M. pneumoniae N602 (b subfamily of F0F1-ATPase), M. pneumoniae N162 and M. pneumoniae N611 (69). Specifically, the inflammatory capacity of M. pneumoniae N602 is higher ( 100-fold), compared with that of M. pneumoniae N161 and M. pneumoniae N162, indicating that M. pneumoniae N602 is a potential superantigen component $(70,71)$.

Immunosuppression. M. pneumoniae infection can induce immunosuppression in the body and cause maladjustment of T cell subgroups. Experiments have revealed that M. pneumoniae infection causes severe destruction of $\mathrm{B}$ cells and $\mathrm{T}$ cells (72). At 13-18 weeks in patients infected with M. pneumoniae, the serum level of IgG declines (73). Certain children infected with M. pneumoniae suffer from hypoglobulinemia, decreased chemoattraction in neutrophils, lower reactivity to 
phytohemagglutin phytolectin and reduced resistance against combined infections with other pathogens, including $S$. pneumoniae (72). These changes indicate that $M$. pneumoniae infection may induce immunosuppression.

\section{Conclusion and perspective}

As summarized in the present review, it has been demonstrated over several years that the pathogenesis of M. pneumoniae infection is complex; the natural synergy between the various factors involved is summarized in Fig. 1. There is no one factor alone, which is involved. As increased efforts have focussed on investigating M. pneumoniae gene structures and functions, and in sequencing, the various pathogenic factors of $M$. pneumoniae membrane proteins, invasive proteins and adhesive proteins can be investigated at the molecular level. This development not only assists with the treatment and prevention of $M$. pneumoniae infection, but is also meaningful for the development of Mycoplasma vaccines.

\section{Acknowledgements}

This study was supported by the National Natural Science Foundation of China (grant no. 31100137), the Natural Science Foundation of Hunan Proince (grant no. 14JJ7044), the Project Foundation of Health Department of Hunan Province (grant no. B2011-058) and the 12th Five-Year Technology Innovation Team at the University of South China.

\section{References}

1. Roca B: Mycoplasma infections. Rev Clin Esp 206: 239-242, 2006 (In Spanish).

2. Ubukata K: Mycoplasma pneumoniae. Nihon Yakurigaku Zasshi 141: 287-289, 2013 (In Japanese).

3. Özel C, Dafotakis M, Nikoubashman O, Litmathe J, Matz O and Schöne U: Mycoplasma pneumoniae-induced meningoencephalitis. Fortschr Neurol Psychiatr 83: 392-396, 2015 (In German).

4. Atkinson TP and Waites KB: Mycoplasma pneumoniae infections in childhood. Pediatr Infect Dis J 33: 92-94, 2014.

5. Fan Q, Meng J, Li P, Liu Z, Sun Y and Yan P: Pathogenesis and association of Mycoplasma pneumoniae infection with cardiac and hepatic damage. Microbiol Immunol 59: 375-380, 2015.

6. Shimizu T, Kimura Y, Kida Y, Kuwano K, Tachibana M, Hashino M and Watarai M: Cytadherence of Mycoplasma pneumoniae induces inflammatory responses through autophagy and toll-like receptor 4. Infect Immun 82: 3076-3086, 2014.

7. Prince OA, Krunkosky TM and Krause DC: In vitro spatial and temporal analysis of Mycoplasma pneumoniae colonization of human airway epithelium. Infect Immun 82: 579-586, 2014.

8. Balish MF: Mycoplasma pneumoniae, an underutilized model for bacterial cell biology. J Bacteriol 196: 3675-3682, 2014.

9. Chourasia BK, Chaudhry R and Malhotra P: Delineation of immunodominant and cytadherence segment(s) of Mycoplasma pneumoniae P1 gene. BMC Microbiol 14: 108, 2014.

10. Waldo RH III and Krause DC: Synthesis, stability, and function of cytadhesin P1 and accessory protein B/C complex of Mycoplasma pneumoniae. J Bacteriol 188: 569-575, 2006.

11. Seto S, Kenri T, Tomiyama T and Miyata M: Involvement of P1 adhesin in gliding motility of Mycoplasma pneumoniae as revealed by the inhibitory effects of antibody under optimized gliding conditions. J Bacteriol 187: 1875-1877, 2005.

12. Willby MJ, Balish MF, Ross SM, Lee KK, Jordan JL and Krause DC: HMW1 is required for stability and localization of HMW2 to the attachment organelle of Mycoplasma pneumoniae. J Bacteriol 186: 8221-8228, 2004.

13. Page CA and Krause DC: Protein kinase/phosphatase function correlates with gliding motility in Mycoplasma pneumoniae. J Bacteriol 195: 1750-1757, 2013.
14. Chaudhry R, Varshney AK and Malhotra P: Adhesion proteins of Mycoplasma pneumoniae. Front Biosci 12: 690-699, 2007.

15. Chang HY, Prince OA, Sheppard ES and Krause DC: Processing is required for a fully functional protein P30 in Mycoplasma pneumoniae gliding and cytadherence. J Bacteriol 193: 5841-5846, 2011.

16. Chang HY, Jordan JL and Krause DC: Domain analysis of protein P30 in Mycoplasma pneumoniae cytadherence and gliding motility. J Bacteriol 193: 1726-1733, 2011.

17. Cloward JM and Krause DC: Loss of co-chaperone TopJ impacts adhesin $\mathrm{P} 1$ presentation and terminal organelle maturation in Mycoplasma pneumoniae Mol Microbiol 81: 528-539, 2011.

18. Kannan TR, Musatovova O, Balasubramanian S, Cagle M, Jordan JL, Krunkosky TM, Davis A, Hardy RD and Baseman JB: Mycoplasma pneumoniae community acquired respiratory distress syndrome toxin expression reveals growth phase and infection-dependent regulation. Mol Microbiol 76: 1127-1141, 2010.

19. Ledford JG, Goto H, Potts EN, Degan S, Chu HW, Voelker DR, Sunday ME, Cianciolo GJ, Foster WM, Kraft M and Wright JR: SP-A preserves airway homeostasis during Mycoplasma pneumoniae infection in mice. J Immunol 182: 7818-7827, 2009.

20. Balish MF, Santurri RT, Ricci AM, Lee KK and Krause DC: Localization of Mycoplasma pneumoniae cytadherence-associated protein HMW2 by fusion with green fluorescent protein: Implications for attachment organelle structure. Mol Microbiol 47: 49-60, 2003.

21. Bao S, Yu S, Guo X, Zhang F, Sun Y, Tan L, Duan Y, Lu F, Qiu X and Ding C: Construction of a cell-surface display system based on the N-terminal domain of ice nucleation protein and its application in identification of Mycoplasma adhesion proteins. J Appl Microbiol 119: 236-244, 2015.

22. Großhennig S, Schmidl SR, Schmeisky G, Busse J and Stülke J: Implication of glycerol and phospholipid transporters in Mycoplasma pneumoniae growth and virulence. Infect Immun 81: 896-904, 2013.

23. Schomburg J and Vogel M: A 12-year-old boy with severe mucositis: Extrapulmonary manifestation of Mycoplasma pneumoniae infection. Klin Padiatr 224: 94-95, 2012.

24. Li S, Li X, Wang Y, Yang J, Chen Z and Shan S: Global secretome characterization of A549 human alveolar epithelial carcinoma cells during Mycoplasma pneumoniae infection. BMC Microbiol 14: 27, 2014.

25. Meseguer MA, Alvarez A, Rejas MT, Sánchez C, Pérez-Diaz JC and Baquero F: Mycoplasma pneumoniae: A reduced-genome intracellular bacterial pathogen. Infect Genet Evol 3: 47-55, 2003.

26. Meyer Sauteur PM, Huber BM and Goetschel P: Neuroinvasive Mycoplasma pneumoniae infection without intrathecal antibody response. Pediatr Infect Dis J 31: 1199-1200, 2012.

27. Rhodes RH, Monastersky BT, Tyagi R and Coyne T: Mycoplasmal cerebral vasculopathy in a lymphoma patient: Presumptive evidence of Mycoplasma pneumoniae microvascular endothelial cell invasion in a brain biopsy. J Neurol Sci 309: 18-25, 2011.

28. McDermott AJ, Taylor BM and Bernstein KM: Toxic epidermal necrolysis from suspected Mycoplasma pneumoniae infection. Mil Med 178: e1048-e1050, 2013.

29. Calvano RA, Scacchi MF, Sojo MM, Diaz SM, Volonteri VI and Giachetti AC: Toxic epidermal necrolysis associated with acute infection by Mycoplasma pneumoniae. Arch Argent Pediatr 111: e24-e27, 2013 (In Spanish).

30. Elkhal CK, Kean KM, Parsonage D, Maenpuen S, Chaiyen P, Claiborne A and Karplus PA: Structure and proposed mechanism of L- $\alpha$-glycerophosphate oxidase from Mycoplasma pneumoniae. FEBS J 282: 3030-3042, 2015.

31. Maenpuen S, Watthaisong P, Supon P, Sucharitakul J, Parsonage D, Karplus PA, Claiborne A and Chaiyen P: Kinetic mechanism of L- $\alpha$-glycerophosphate oxidase from Mycoplasma pneumoniae. FEBS J 282: 3043-3059, 2015.

32. Ledford JG, Mukherjee S, Kislan MM, Nugent JL, Hollingsworth JW and Wright JR: Surfactant protein-A suppresses eosinophil-mediated killing of Mycoplasma pneumoniae in allergic lungs. PLoS One 7: e32436, 2012.

33. Sun G, Xu X, Wang Y, Shen X, Chen Z and Yang J: Mycoplasma pneumoniae infection induces reactive oxygen species and DNA damage in A549 human lung carcinoma cells. Infect Immun 76: 4405-4413, 2008.

34. Kariya C, Chu HW, Huang J, Leitner H, Martin RJ and Day BJ: Mycoplasma pneumoniae infection and environmental tobacco smoke inhibit lung glutathione adaptive responses and increase oxidative stress. Infect Immun 76: 4455-4462, 2008. 
35. Inaba H, Geiger TL, Lasater OE and Wang WC: A case of hemoglobin SC disease with cold agglutinin-induced hemolysis. Am J Hematol 78: 37-40, 2005.

36. Hardy RD, Coalson JJ, Peters J, Chaparro A, Techasaensiri C, Cantwell AM, Kannan TR, Baseman JB and Dube PH: Analysis of pulmonary inflammation and function in the mouse and baboon after exposure to Mycoplasma pneumoniae CARDS toxin. PLoS One 4: e7562, 2009.

37. Techasaensiri C, Tagliabue C, Cagle M, Iranpour P, Katz K, Kannan TR, Coalson JJ, Baseman JB and Hardy RD: Variation in colonization, ADP-ribosylating and vacuolating cytotoxin, and pulmonary disease severity among Mycoplasma pneumoniaestrains. Am J Respir Crit Care Med 182: 797-804, 2010.

38. Somarajan SR, Al-Asadi F, Ramasamy K, Pandranki L, Baseman JB and Kannan TR: Annexin A2 mediates Mycoplasma pneumoniae community-acquired respiratory distress syndrome toxin binding to eukaryotic cells. MBio 5: pii: e01497-14, 2014.

39. Medina JL, Coalson JJ, Brooks EG, Le Saux CJ, Winter VT, Chaparro A, Principe MF, Solis L, Kannan TR, Baseman JB and Dube PH: Mycoplasma pneumoniae CARDS toxin exacerbates ovalbumin-induced asthma-like inflammation in BALB/c mice. PLoS One 9: e102613, 2014.

40. Johnson C, Kannan TR and Baseman JB: Cellular vacuoles induced by Mycoplasma pneumoniae CARDS toxin originate from Rab9-associated compartments. PLoS One 6: e22877, 2011

41. Kim EK, Youn YS, Rhim JW, Shin MS, Kang JH and Lee KY: Epidemiological comparison of three Mycoplasma pneumoniae pneumonia epidemics in a single hospital over 10 years. Korean J Pediatr 58: 172-177, 2015.

42. Lynch M, Taylor TK, Duignan PJ, Swingler J, Marenda M, Arnould JP and Kirkwood R: Mycoplasmas in Australian fur seals (Arctocephalus pusillus doriferus): Identification and association with abortion. J Vet Diagn Invest 23: 1123-1130, 2011

43. Lai JF, Zindl CL, Duffy LB, Atkinson TP, Jung YW, van Rooijen N, Waites KB, Krause DC and Chaplin DD: Critical role of macrophages and their activation via MyD88-NFKB signaling in lung innate immunity to Mycoplasma pneumoniae. PLoS One 5: e14417, 2010.

44. Halbedel S, Hames C and Stülke J: In vivo activity of enzymatic and regulatory components of the phosphoenolpyruvate: Sugar phosphotransferase system in Mycoplasma pneumoniae. J Bacteriol 186: 7936-7943, 2004.

45. Beersma MF, Dirven K, van Dam AP, Templeton KE, Claas EC and Goossens H: Evaluation of 12 commercial tests and the complement fixation test for Mycoplasma pneumoniae-specific immunoglobulin $\mathrm{G}(\mathrm{IgG})$ and IgM antibodies, with PCR used as the 'gold standard'. J Clin Microbiol 43: 2277-2285, 2005.

46. Loos $\mathrm{M}$ and Brunner $\mathrm{H}$ : Complement components $(\mathrm{C} 1, \mathrm{C} 2, \mathrm{C} 3$, $\mathrm{C} 4)$ in bronchial secretions after intranasal infection of guinea pigs with Mycoplasma pneumoniae: Dissociation of unspecific and specific defense mechanisms. Infect Immun 25: 583-585, 1979.

47. Thacker WL and Talkington DF: Analysis of complement fixation and commercial enzyme immunoassays for detection of antibodies to Mycoplasma pneumoniae in human serum. Clin Diagn Lab Immunol 7: 778-780, 2000.

48. Tuuminen T and Vainionpää R: Development of enzyme immunoassays to detect salivary sIgA to Chlamydia pneumoniae and Mycoplasma pneumoniae. Scand J Clin Lab Invest 61: 357-362, 2001.

49. Daxböck F, Brunner G, Popper H, Krause R, Schmid K, Krejs GJ and Wenisch C: A case of lung transplantation following Mycoplasma pneumoniae infection. Eur J Clin Microbiol Infect Dis 21: 318-322, 2002

50. Csángó PA, Pedersen JE and Hess RD: Comparison of four Mycoplasma pneumoniae IgM-, IgG- and IgA-specific enzyme immunoassays in blood donors and patients. Clin Microbiol Infect 10: 1094-1098, 2004

51. Venancio P, Brito MJ, Pereira $G$ and Vieira JP: Anti-N-methyl-D-aspartate receptor encephalitis with positive serum antithyroid antibodies, IgM antibodies against Mycoplasma pneumoniae and human herpesvirus 7 PCR in the CSF. Pediatr Infect Dis J 33: 882-883, 2014.

52. Smith-Norowitz TA, Silverberg JI, Kusonruksa M, Weaver D, Ginsburg D, Norowitz KB, Durkin HG, Hammerschlag MR, Bluth MH and Kohlhoff SA: Asthmatic children have increased specific anti-Mycoplasma pneumoniae IgM but not IgG or IgE-values independent of history of respiratory tract infection. Pediatr Infect Dis J 32: 599-603, 2013.
53. Ye Q, Xu XJ, Shao WX, Pan YX and Chen XJ: Mycoplasma pneumoniae infection in children is a risk factor for developing allergic diseases. ScientificWorldJournal 2014: 986527, 2014.

54. Xin LH, Wang J, Wang Z, Cheng W and Zhang W: Effect of Mycoplasma pneumoniae infection on function of T lymphocytes in bronchoalveolar lavage fluid of asthmatic children. Zhongguo Dang Dai Er Ke Za Zhi 16: 277-280, 2014 (In Chinese).

55. Kang YM, Ding MJ, Han YL, Wang SF, Ma X and Li H: Th1/Th2 immune response in bronchoalveolar lavage fluid in children with severe Mycoplasma pneumoniae pneumonia. Zhongguo Dang Dai Er Ke Za Zhi 13: 188-190, 2011 (In Chinese).

56. Pang HX, Qiao HM, Cheng HJ, Zhang YF, Liu XJ and Li JZ: Levels of TNF-alpha, IL-6 and IL-10 in bronchoalveolar lavage fluid in children with Mycoplasma pneumoniae pneumonia. Zhongguo Dang Dai Er Ke Za Zhi 13: 808-810, 2011 (In Chinese).

57. Yang J, Hooper WC, Phillips DJ and Talkington DF: Regulation of proinflammatory cytokines in human lung epithelial cells infected with Mycoplasma pneumoniae. Infect Immun 70: 3649-3655, 2002

58. Lee KE, Kim KW, Hong JY, Kim KE and Sohn MH: Modulation of IL-8 boosted by Mycoplasma pneumoniae lysate in human airway epithelial cells. J Clin Immunol 33: 1117-1125, 2013.

59. He JE, Gao CY and Li HR: Effect of low-dose methylprednisolone on serum TNF- $\alpha$ level in children with Mycoplasma pneumoniae pneumonia. Zhongguo Dang Dai Er Ke Za Zhi 15: 850-853, 2013 (In Chinese).

60. Tanaka H, Narita M, Teramoto S, Saikai T, Oashi K, Igarashi T and Abe S: Role of interleukin-18 and T-helper type 1 cytokines in the development of Mycoplasma pneumoniae pneumonia in adults. Chest 121: 1493-1497, 2002.

61. Krunkosky TM, Jordan JL, Chambers E and Krause DC: Mycoplasma pneumoniae host-pathogen studies in an air-liquid culture of differentiated human airway epithelial cells. Microb Pathog 42: 98-103, 2007.

62. Kurata S, Osaki T, Yonezawa H, Arae K, Taguchi H and Kamiya S: Role of IL-17A and IL-10 in the antigen induced inflammation model by Mycoplasma pneumoniae. BMC Microbiol 14: 156 , 2014.

63. Teig N, Anders A, Schmidt C, Rieger C and Gatermann S: Chlamydophila pneumoniae and Mycoplasma pneumoniae in respiratory specimens of children with chronic lung diseases. Thorax 60: 962-966, 2005.

64. Fink FM, Dengg K, Kilga-Nogler S, Schönitzer D and Berger H: Cold haemagglutinin disease complicating Mycoplasma pneumoniae infection in a child under cytotoxic cancer treatment. Eur J Pediatr 151: 435-437, 1992

65. Busolo F, Tonellato L, Scremin L, Tonin E, Bertoloni G and Franceschi C: Phagocytosis of Mycoplasma pneumoniae and Acholeplasma laidlawii measured as inhibition of $[3 \mathrm{H}]$ uridine uptake by macrophages. J Immunol Methods 90: 235-240, 1986.

66. Kornspan JD, Tarshis M and Rottem S: Adhesion and biofilm formation of Mycoplasma pneumoniae on an abiotic surface. Arch Microbiol 193: 833-836, 2011.

67. Hon KL, Ip M, Chu WC and Wong W: Megapneumonia coinfection: Pneumococcus, Mycoplasma pneumoniae, and Metapneumovirus. Case Rep Med 2012: 310104, 2012.

68. Hausner M, Schamberger A, Naumann W, Jacobs E and Dumke R: Development of protective anti-Mycoplasma pneumoniae antibodies after immunization of guinea pigs with the combination of a P1-P30 chimeric recombinant protein and chitosan. Microb Pathog 64: 23-32, 2013.

69. Shimizu T, Kida Y and Kuwano K: A dipalmitoylated lipoprotein from Mycoplasma pneumoniae activates NF-kappa B through TLR1, TLR2, and TLR6. J Immunol 175: 4641-4646, 2005.

70. Into T, Dohkan J, Inomata M, Nakashima M, Shibata K and Matsushita K: Synthesis and characterization of a dipalmitoylated lipopeptide derived from paralogous lipoproteins of Mycoplasma pneumoniae. Infect Immun 75: 2253-2259, 2007.

71. Shimizu T, Kida Y and Kuwano K: Triacylated lipoproteins derived from Mycoplasma pneumoniae activate nuclear factor-kappaB through toll-like receptors 1 and 2 . Immunology 121: 473-483, 2007.

72. Okoli K, Gupta A, Irani F and Kasmani R: Immune thrombocytopenia associated with Mycoplasma pneumoniae infection: A case report and review of literature. Blood Coagul Fibrinolysis 20: 595-598, 2009.

73. Rastawicki W, Rokosz N and Jagielski M: Subclass distribution of human IgG antibodies to Mycoplasma pneumoniae in the course of mycoplasmosis. Med Dosw Mikrobiol 61: 375-379, 2009 (In Polish). 